\section{Real-Time Quantitative RT-PCR Assay of Gene Expression in Plant Roots during Fungal Pathogenesis}

BioTechniques 34:982-986 (May 2003)

\begin{abstract}
Real-time quantitative RT-PCR is becoming the preferred method for high-sensitivity, rapid-throughput $R N A$ transcript quantification. However, due to the significant developmental costs of dedicated fluorogenic probes, a real-time assay that is simple to establish, comparatively inexpensive, and readily adaptable would be advantageous for the detailed analysis of large sets of expressed sequences. We have devised a flexible real-time quantitative $R T$ PCR assay that employs a nonspecific DNA binding dye for product detection and uses a relative quantification formula to account for differences in PCR amplification efficiency between the target and reference products. The latter permits the use of an exogenous reference transcript and therefore avoids the normal requirement for the construction of a recombinant $R N A$ reference transcript or extensive characterization of housekeeping gene expression. In an investigation of class II chitinase expression in two varieties of Bermuda grass (Cynodon spp.), following infection with the fungal root pathogen Ophiosphaerella narmari, this assay identified 16- and 28-fold peaks in gene expression at 24 and $96 \mathrm{~h}$ after inoculation, respectively.
\end{abstract}

\section{INTRODUCTION}

Spring dead spot of Bermuda grass (Cynodon spp.), caused by the fungal root pathogen Ophiosphaerella narmari, is the most important disease complex identified in turf grasses in Australia and the United States. The characterization and manipulation of host plant resistance is a possible strategy for effective disease control. Most plants possess pathogenesis-related proteins, such as chitinase and glu- canase, which are encoded by genes that are rapidly induced following pathogen infection. Chitinase degrades chitin ( $\mathrm{N}$-acetylglucosamine $)_{\mathrm{n}}$, a major structural polymer of the fungal cell wall, and these enzymes have been shown to halt the growth of some fungi in vitro $(1,2)$. Moreover, the expression of class II chitinase transgenes has increased the resistance of wheat to fungal pathogens $(3,4)$. Investigation of the expression of class II chitinase mRNA in the roots of Bermuda grass varieties during fungal infection may indicate the importance of such genes in host plant resistance toward $O$. narmari.

In recent years, quantitative RTPCR has become the method of choice for high-sensitivity, rapid-throughput quantification of mRNA. Following reverse transcription, PCR amplification products can be detected by fluorescent emission from sequence-specific, fluorogenic oligonucleotides such as TaqMan ${ }^{\circledR}$ (Applied Biosystems, Foster City, CA, USA) (5), molecular beacons (6) or dual fluorescence resonance energy transfer (FRET) probes (7), or from nonspecific dsDNA binding dyes (8). Instruments that can detect a range of fluorescence chemistries instantaneously (in real time) have added to the utility of the technique and provide an abundance of options for any experiment $(9,10)$.

A real-time quantitative RT-PCR assay that is easy to establish and highly adaptable yet economical to operate would be invaluable for projects with limited budgets or when large sets of expressed sequence tags (ESTs) or microarray data require further analysis. Lowcost assays inevitably use dye-based detection and are restricted to rel- ative quantification against an endogenous (housekeeping) gene or an exogenous reference transcript. However, housekeeping genes need to be identified and have their expression confirmed as invariant under broad experimental conditions before they can be validly used as reference transcripts.

Here we report the development of a convenient and flexible real-time quantitative RT-PCR assay that uses an exogenously derived reference transcript and SYBR ${ }^{\circledR}$ green I detection. This is combined with a relative quantification formula that accounts for differences in PCR amplification efficiency between the target and reference products (11). The assay was found to be suitable for the analysis of variable chitinase transcript levels in Cynodon spp. roots during fungal pathogenesis.

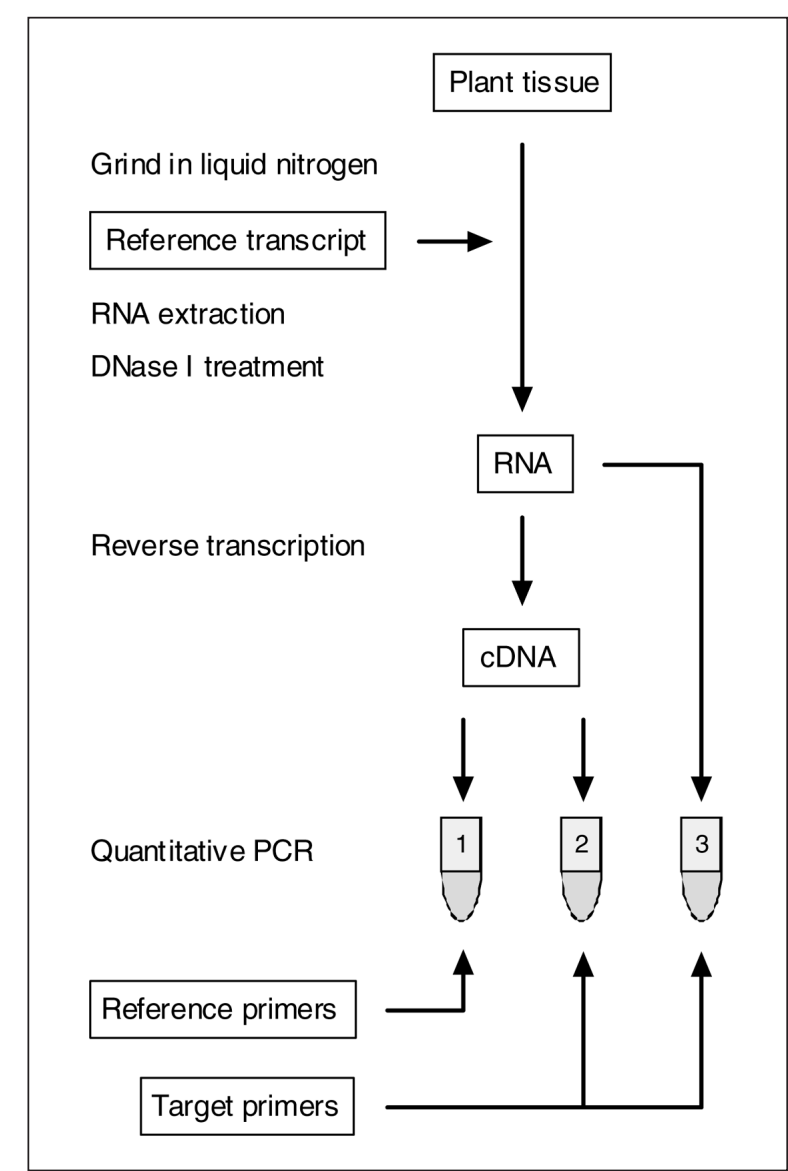

Figure 1. Design of the quantitative RT-PCR assay. The RNA of the reference transcript (Kan 1.2) is added before RNA extraction. The pooled RNA is treated with DNase I and then reverse transcribed. Quantitative reactions are conducted in triplicate. Paired tubes receive equivalent cDNA from either the reference (1) or target (2) primer pairs. To control for DNA contamination, a third tube without cDNA template also receives the target primers (3). 


\section{MATERIALS AND METHODS}

Four-week-old, axenically propagated Bermuda grass (Cynodon spp.) plants were transferred into liquid hormone- and sucrose-free Murashige and Skoog media and incubated in constant high-light conditions with rotary shaking at $100 \mathrm{rpm}$ (12). O. narmari inoculum was a homogenate of eight-weekold potato dextrose agar (PDA) culture plates. Propagule numbers were estimated by an adaptation of the most probable number method, in which the serial dilutions were cultured on PDA plates (13). Plant roots were infected by the addition of approximately $1000 O$. narmari propagules to each culture vessel. Uninfected plants received a water control, and root tissue was harvested at $0,12,24,48$, or $96 \mathrm{~h}$ after infection.

The RNA was isolated using the RNeasy $^{\circledR}$ plant RNA extraction kit (Qiagen, Clifton Hill, Victoria, Aus- tralia) with elution for $10 \mathrm{~min}$ in $50 \mu \mathrm{L}$ RNase-free water. Root tissue (100 mg) was ground into a fine powder in liquid nitrogen and dispersed into extraction buffer. Approximately $2.5 \times 10^{5}$ copies of Kanamycin $1.2 \mathrm{~kb}$ Control RNA (Kan 1.2; Promega, Madison, WI, USA) were then added to each extraction. After elution, $40 \mathrm{U}$ RNaseOUT ${ }^{\mathrm{TM}}$ RNase inhibitor (Invitrogen, Carlsbad, CA, USA) were added to each sample. RNA integrity was assessed by examining the rRNA bands after electophoresis on a standard agarose gel. Contaminating DNA was then removed using DNA-free ${ }^{\mathrm{TM}}$ (Ambion, Austin, TX, USA) with 4 U DNase I per sample and incubation for $1 \mathrm{~h}$.

Reverse transcription was performed in a total volume of $20 \mu \mathrm{L}$. Total RNA amounts were not normalized between reactions. Total RNA solution $(12 \mu \mathrm{L})$ was combined with $500 \mathrm{ng}$ oligo $(\mathrm{dT})_{18}$ primer $(1 \mu \mathrm{L})$, heated at $70^{\circ} \mathrm{C}$ for $10 \mathrm{~min}$, and cooled on ice. Each reaction tube then received $4 \mu \mathrm{L}$ of $5 \times$ first-strand buffer (Invitrogen), $2 \mu \mathrm{L}$ $0.1 \mathrm{M}$ DTT, $1 \mu \mathrm{L} 10 \mathrm{mM}$ of dNTPs, and $100 \mathrm{U}^{\text {SuperScript }}{ }^{\mathrm{TM}}$ II RNase $\mathrm{H}^{-}$ reverse transcriptase (Invitrogen) as a master mixture. Control tubes (RT-) for each sample received a mixture with no enzyme. The reactions were incubated at $25^{\circ} \mathrm{C}$ for $10 \mathrm{~min}$ (primer annealing) and at $50^{\circ} \mathrm{C}$ for $50 \mathrm{~min}$ (cDNA synthesis). The cDNA solutions were then treated with $1 \mathrm{U}$ RNase $\mathrm{H}$ (Fermentas, Vilnius, Lithuania) for $30 \mathrm{~min}$ at $37^{\circ} \mathrm{C}$, and cDNA solutions and controls were diluted 10-fold to a final volume of 200 $\mu \mathrm{L}$ with sterile Milli-Q ${ }^{\circledR}$ water (Millipore, Bedford, MA, USA).

Quantitative PCR was performed in a 32-well Rotor-Gene ${ }^{\mathrm{TM}}$ centrifugal realtime thermal cycler (Corbett Research, Mortlake, NSW, Australia). Each quantitative PCR contained $2.5 \mathrm{mM} \mathrm{MgCl}_{2}$, $1 \times$ reaction buffer $(20 \mathrm{mM}$ Tris- $\mathrm{HCl}, \mathrm{pH}$ 


\section{Short Technical Reports}

8.4, $50 \mathrm{mM} \mathrm{KCl}), 200 \mathrm{nM}$ of each dNTP, $5 \mu \mathrm{L}$ of template (RT/RT-), $0.1 \times$ SYBR green I (Molecular Probes, Eugene, OR, USA), $0.5 \mathrm{U}$ of recombinant Taq DNA polymerase (Invitrogen), and $200 \mathrm{nM}$ of each primer for either target or reference primer pair in a total reaction volume of $25 \mu \mathrm{L}$. CHTIIa (target) PCR primers were sense $5^{\prime}$-ACCAGGCCCAACCTCGAT-3' and antisense 5'CGGATTGAATCTACACATTGACA3'. Kan 1.2 (reference) PCR primers were sense 5'-GCCATTCTCACCGGATTCAGTCGTC- ${ }^{\prime}$ and antisense $5^{\prime}$ AGCCGCCGTCCCGTCAAGTCAG-3' (Promega). Both primer pairs were optimized for equivalent annealing temperatures. The thermal profile for quantitative PCR was $94^{\circ} \mathrm{C}$ for $3 \mathrm{~min}$, and then $94^{\circ} \mathrm{C}$ for $15 \mathrm{~s}, 60^{\circ} \mathrm{C}$ for $1 \mathrm{~min}, 15 \mathrm{~s}$ at $80^{\circ} \mathrm{C}$ (fluorescence measurement) repeated for 50 cycles, followed by a melting step in which the temperature was raised in one-degree increments from $50^{\circ} \mathrm{C}$ to $99^{\circ} \mathrm{C}$ with a 5 -s hold at each degree.

The identity of each RT-PCR product was confirmed initially by direct sequencing and subsequently from the observation of a single melt peak in the respective reactions. Every quantitative PCR run contained "no template" controls for each primer pair. The 134-bp CHTIIa and 323-bp Kan 1.2 products were cloned into $\mathrm{pBluescript}^{\circledR} \mathrm{SK}^{+}$ (Stratagene, La Jolla, CA, USA), and pCHTIIa and pKan323 were serially diluted over a five-log range from $10^{5}$ to $10^{1}$ molecules. PCRs were per- formed with the points in the two dilution series as templates. The threshold was set at 0.15 fluorescent units, and the threshold cycle $\left(C_{t}\right)$ values were plotted against the log of starting template concentration (5). The slope $m$ of the line $y=m x+b$ is related to the amplification efficiency by the formula $\mathrm{E}$ $=10^{[-1 / \mathrm{m}]}(14)$. The fold change in CHTIIa expression during fungal infection was calculated from the $\mathrm{C}_{t}$ values and the PCR amplification efficiencies using the formula (11):

fold change $=\frac{\left(\mathrm{E}_{\text {target }}\right)^{\Delta \mathrm{C} \text { target }}(\text { control - infected })}{\left(\mathrm{E}_{\text {ref }}\right)^{\Delta \mathrm{C} \mathrm{t}_{\text {ref }}(\text { control } \text { - infected })}}$

[Eq. 1]

\section{RESULTS}

The process of sampling limited stocks of axenically propagated plant tissue at multiple timepoints, combined with the relatively low yields of RNA harvested from infected Bermuda grass roots (data not shown), required the development of a highly sensitive method for the detection of chitinase gene transcripts. Figure 1 shows the components of the two-step quantitative RT-PCR assay system. To provide an internal reference for each sample, a heterologous kanamycin transcript (Kan 1.2 RNA) was added during the RNA extraction, co-transcribed with the target transcript in the reverse transcription reaction, and PCR amplified separately to the target.
A partial class II chitinase gene clone was obtained by the amplification of Cynodon spp. genomic DNA with degenerate primers designed from conserved plant chitinase sequences, and PCR walking was used to extend the $3^{\prime}$ sequences of this clone to create a chitinase gene contig that was designated CHTIIa (data not shown). The specific PCR primers designed from this contig encompass 42 bp of the CHTIIa open reading frame together with $92 \mathrm{bp}$ of the $3^{\prime}$ untranslated region and amplify a single 134bp CHTIIa product from the genomic DNA of the two Bermuda grass varieties, "Greenlees Park" (GLP) and "Tifgreen" (TG).

For both the CHTIIa target and Kan 1.2 reference products, Pearson correlation coefficients confirmed the relationship between starting template concentration and $\mathrm{C}_{\mathrm{t}}$ value (Figure 2). PCR amplification efficiencies were 1.90 for the CHTIIa product and 1.97 for the Kan 1.2 reference product. To test the low level of variability in the assay, the Kan 1.2 reference was amplified from 15 different cDNA backgrounds in a total of 87 replicates and gave a mean $\mathrm{C}_{\mathrm{t}}$ value of 19.88 cycles with a variation of $3.2 \%$.

Root tissue from the Bermuda grass varieties GLP and TG was harvested at $0,12,24,48$, and $96 \mathrm{~h}$, following inoculation with propagules of the $O$. narmari pathogen. Fold changes in the levels of CHTIIa gene transcripts were determined using the quantitative RTPCR assay (Figure 3). The expression

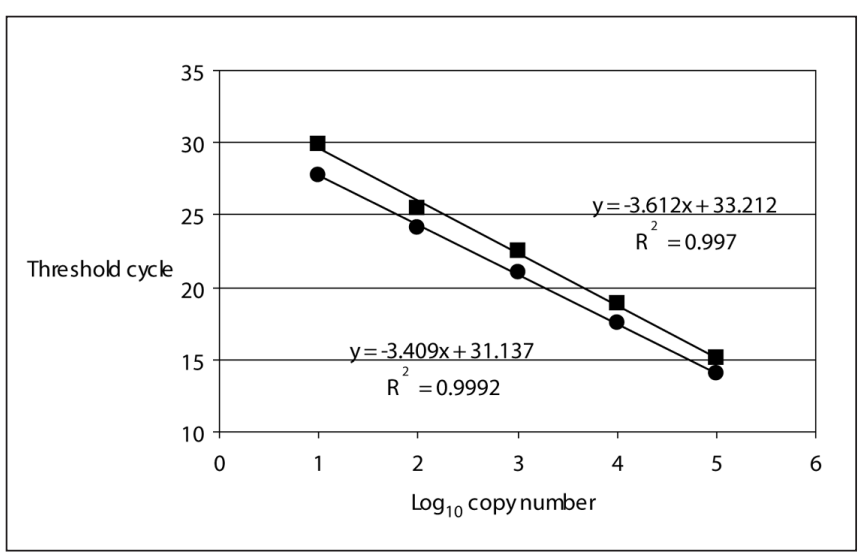

Figure 2. Amplification efficiencies of CHTIIa and Kan 1.2 products. Threshold cycle $\left(\mathrm{C}_{t}\right)$ for the CHTIIa $(\mathbf{\square})$ and Kan $1.2(\mathbf{O})$ products plotted against $\log _{10}$ of the known number of starting template molecules in the dilution series. The line equations and Pearson correlation coefficients $\left(\mathrm{R}^{2}\right)$ are given.

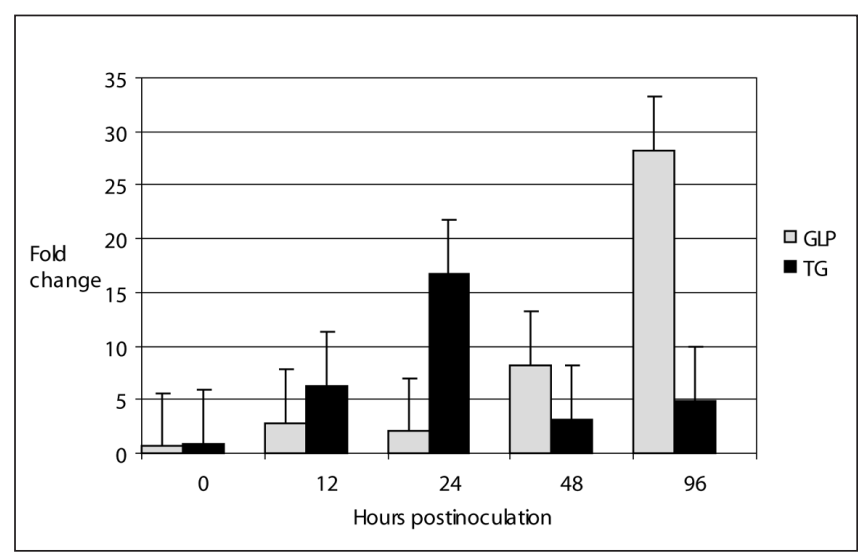

Figure 3. Bermuda grass chitinase mRNA expression during fungal pathogenesis. Fold change in the expression of CHTIIa mRNA in the two Cynodon spp. varieties, GLP and TG, at 0, 12, 24, 48 and $96 \mathrm{~h}$ after inoculation with $O$. narmari propagules. 


\section{Short Technical Reports}

of CHTIIa in TG was shown to peak 16fold after only $24 \mathrm{~h}$, whereas CHTIIa expression in GLP achieved a larger but delayed increase of 28 -fold after $96 \mathrm{~h}$.

\section{DISCUSSION}

The aim of this work was to develop a cost-effective, real-time quantitative RT-PCR assay suitable for the analysis of mRNA levels in Cynodon roots during microbial pathogenesis. Our data show that the resultant assay can accurately detect changes in transcript levels in small samples of Bermuda grass tissue at progressive stages of fungal infection. The quantitative RT-PCR assay was sensitive, highly reproducible, and comparatively inexpensive to set up and operate.

The devised assay structure has several advantages. The use of an exogenous reference transcript avoids the need to construct a recombinant RNA reference or to confirm the expression of housekeeping genes as invariant under experimental conditions. Such a reference transcript is adjustable toward the range of the target and is not subject to temporal variation. The addition of the reference RNA to the nucleic acid extraction limits error to single mass and volume measurements and controls for the yield and quality of RNA. Thus, the problem of normalizing sample RNA of low concentration between reactions is eliminated. In addition, the reference transcript used here is commercially available, thus avoiding in vitro transcription and purification. We suggest that reverse transcriptase inhibition would influence all of the transcripts within a reaction equally and that differences in reversetranscription efficiency between any two transcripts due to sequence composition would be at a fixed ratio.

It should be noted that the use of a heterologous reference transcript would not normally provide for matched PCR amplification efficiencies between the reference and target products. However, this requirement can be eliminated by the use of the relative quantification formula, which neatly accounts for any difference in the amplification efficiency between the two products (11). As a result, the assay can be easily adapted for the analysis of alternative or additional target genes using the same reference transcript. The flexibility of the assay is further enhanced by the SYBR green I detection of the amplification products.

The Corbett Research Rotor-Gene PCR machine used in these experiments is centrifugal, and the PCR tubes spin through a single air mass. The low level of variation in the $C_{t}$ values for the reference transcripts shows that the PCR conditions are very uniform and that the external amplification of the reference transcript in paired tubes containing equivalent cDNA templates closely approximates the ideal of an internal RNA reference.

The application of this quantitative PCR assay to the study of fungal pathogenesis in Bermuda grass has indicated a potential role for CHTIIa in host plant defense. However, despite the observed differences in chitinase expression, the chosen cultivars have not been found to differ significantly in their physiological responses to disease (data not shown). Future work might analyze the expression of CHTIIa and other chitinase II genes within a broader selection of Cynodon varieties that exhibit different degrees of disease resistance. The flexibility of the quantitative RT-PCR assay readily lends itself to such expansion. In a more general sense, the assay would be ideal for conducting detailed analyses of microarray data and EST expression in which large sets of genes require investigation and the cost of manifold gene-specific fluorogenic probes would be prohibitive.

\section{REFERENCES}

1.Mauch, F., B. Mauch-Mani, and T. Boller. 1988. Antifungal hydrolases in pea tissue. Plant Physiol. 88:936-942.

2.Schlumbaum, A., F. Mauch, U. Vögeli, and T. Boller. 1986. Plant chitinases are potent inhibitors of fungal growth. Nature 324:365367.

3.Bliffeld, M., J. Mundy, I. Potrykus, and J. Fütterer. 1999. Genetic engineering of wheat for increased resistance to powdery mildew disease. Theor. Appl. Genet. 98:1079-1086.

4.Oldach, K.H., D. Becker, and H. Lörz. 2001. Heterologous expression of genes mediating enhanced fungal resistance in transgenic wheat. Mol. Plant Microbe Interact. 14:832838

5.Heid, C.A., J. Stevens, K. Livak, and P.M.
Williams. 1996. Real-time quantitative PCR Genome Res. 6:986-994.

6.Tyagi, S. and F.R. Kramer. 1996. Molecular beacons-probes that fluoresce upon hybridization. Nat. Biotechnol. 14:303-308.

7.Wittwer, C.T., K.M. Ririe, R.V. Andrew, D.A. David, R.A. Gundry, and U.J. Balis. 1997. Continuous fluorescence monitoring of rapid cycle DNA amplification. BioTechniques 22:130-138.

8.Higuchi, R., G. Dollinger, P.S. Walsh, and R. Griffith. 1992. Simultaneous amplification and detection of specific DNA sequences. Nat. Biotechnol. 10:413-417.

9.Giulietti, A., L. Overbergh, D. Valckx, B. Decallonne, R. Bouillon, and C. Mathieu. 2001. An overview of real-time quantitative PCR: applications to quantify cytokine gene expression. Methods 25:386-401.

10.Klein, D. 2002. Quantification using real-time PCR technology: applications and limitations. Trends Mol. Med. 8:257-260.

11.Pfaffl, M.W. 2001. A new mathematical model for relative quantification in real-time RTPCR. Nucleic Acids Res. 29:e45.

12.McMaugh, S.J. and B.R. Lyon. 1997. Molecular genetic analysis of the defensive responses of Cynodon dactylon to the fungal pathogen Leptosphaeria narmari. Int. Turfgrass Soc. Res. J. 8:1166-1175.

13.Cochran, W.G. 1950. Estimation of bacterial densities by means of the "most probable number". Biometrics 6:105-116.

14.Rasmussen, R. 2001. Quantification on the light cycler, p. 21-34. In S. Meuer, C. Wittwer and K. Nakagawara (Eds.), Rapid Cycle RealTime PCR, Methods and Applications. Springer-Verlag, Heidelberg.

The authors would like to thank Dr. Jenny Saleeba for helpful discussions, Dr. Thomas Kaiser from Corbett Research for technical assistance, and Dr. P.T.W. Wong for kindly providing the pathogen isolate. S.J.M. was the recipient of an Australian post-graduate research award. This work was funded by The University of Sydney. Address correspondence to Dr. Bruce R. Lyon, School of Biological Sciences A12, The University of Sydney, Sydney, NSW, 2006, Australia.e-mail:brucel@bio.usyd.edu.au

Received 13 December 2002; accepted 13 February 2003.

\section{Stephen J. McMaugh and Bruce R. Lyon \\ The University of Sydney \\ Sydney, Australia}

